\title{
Exploring Internet of Things (IoT) in Safety and Security Environment
}

\author{
AL Munthir Ali Salim AL-Harthi ${ }^{a}$, and Indrani Palanisamy ${ }^{\mathrm{a}}$
}

\begin{abstract}
Internet of things (IoT) is new technology aimed to achieve the goals of daily life, because every transaction via the Internet and we have to live with it. The aim of this study is to enhance the security and safety objectives to virtually monitor the organizations before the problem occurs as a preventive measure by implementing new monitoring technology using multiple sensors. Internet of things is a new technology in security and safety environment. In this study the implementation of this new technique will focus on the Office of Security and Safety Affairs, which allows them to monitoring through the screen about the work environment in the company and inform the management about the incident such as fire or suffocation in a room by sending an email and also by notification in the screen. In each room we have implemented sensors and through which the data are sent to the servers. This technological development contributes to the organizational growth by controlling any remote device and to take quick decisions in an unforeseen event and provide proper protection during such occurrence. This technological evolution in the name of Internet of things (IoT) in our regular work environment helps to increase remote monitoring and roaming capabilities. This exploratory study based solution is implemented use new things in raspberry pi3 device and the sensor that are connected through internet. This Sensor will monitor occurring in their location and the data is sent to the server in order to monitor security and safety of the organization from control Centre located remotely. This technology also enables communication with the Office of Security and Safety notified about any event, and can send an email alert or notification through their Monitoring screen.

This study is an innovative advent with regard to safety and security, helping to communicate with the human and the network. Internet of Things is nearly the things that can control remotely over internet. This technology helps companies that need the work environment to integrate with Internet of Things, which will help them through it in safety and security matters.
\end{abstract}

Keywords: Internet of Things (IoT), Remote Monitoring, Safety \& Security, Sensors.

\section{Introduction}

Internet of things is new technology achieve the goals of daily life, because every transaction via the Internet and you have to live with it. Internet of things is a new technology in security and safety environment. This new technique will focus on the Office of Security and Safety Affairs, which allows them to monitoring through the screen on the work environment in the company and inform them about the latest incidents such as fire or suffocation in a room by send email and notification in the screen. In each room have sensors and through which the data are sent to the server and so will allow to monitoring all rooms in the company. The aim of the project is to help the security and safety objectives to monitor the campus before the problem occurs, that will make something new to monitoring the building by using multiple of sensors. This project is new in the advent of safety and security, helping to communicate with the man and the network. Internet of Things Nearly the things can control remotely. In this project, we will use the Internet of things to help the Office of Safety and Security, before something is happening in the organizations.

In this report, we obtained data from sensors mounted in the raspberry pi. Therefore they are used as in smart cities (Kobie, 2016). In addition this paper talked about the sensor MQ-2 at a capacity of 5 volts. This low energy cost and also it is small in size and of the advantages they resist changes sensitive element (Shukri, 2016). In addition temperature sensors are used to measure the temperature environment around them (Sean, 2015), this temperature sensor is small in size and operates 5 volts. This paper also investigated Layer 3 \& Layer 2 switches and the smart features in Catalyst 2960 controls access To (ACL) and promote improved security and bandwidth. In addition the existence of encryption technologies Datadependent the ports and the member In MAC addresses (Hucaby, 2009). In addition to easy to build wireless local area networks and it is supported by AP client, to enable different applications to give users a more dynamic experience and ease of wireless network of sites that are difficult to access building wiring (Anon., 2016). In addition to help Organizations to increase and to improve Cooperation between Machines and man, improved the performance firewall capability by implementing CISCO ASA 5520 SECURITY this type provides users Data Security In the network (Jose, S., 2016) The benefits of this literature review for this project to meet the company's needs in terms of surveillance.

\section{Methodology}

Methodology is the theoretical analysis in the field of study for the project, it includes models and stages and methods that help in the passage of the project that determines the way the project was framed for successful implementation. The methodology implemented in this project was prepare plan design implement operate optimize (PPDIOO) model as shown in the "Fig. 1". This method is one of the important methods in any project its help to understand the company needs and archive any project goals or objective. PPDIOO stages are,

1. Prepare: On this step or stage its help to know what the project needs and what the price of the devices for the project. In other hands it helps to know what the important things for 
my project and important needs and what I can use in my project.

2. Plan: this steps help your project to know what is the responsively of your project. In other hand help to know the performance if your project and how its work also what is the size of the network. Also it helps to know what the environment of your project is and analyzes it.

3. Design: in this stage can do many things for example performance, security, It helps to define the style of the project and to know the kin fog your project.

4. Implement: This stage help to know what the component needs for the project and suitable device for the project or project needs.

5. Operate: This stage has many things or help the project to do many things, also to it's the last of the steps of the design, in other hand its help to be your project active also reduce the cost of the devise of the project.

6. Optimize: last step and very important step it help to know the problem and issue of the project and also how to discover the problems and how to solve the problem.

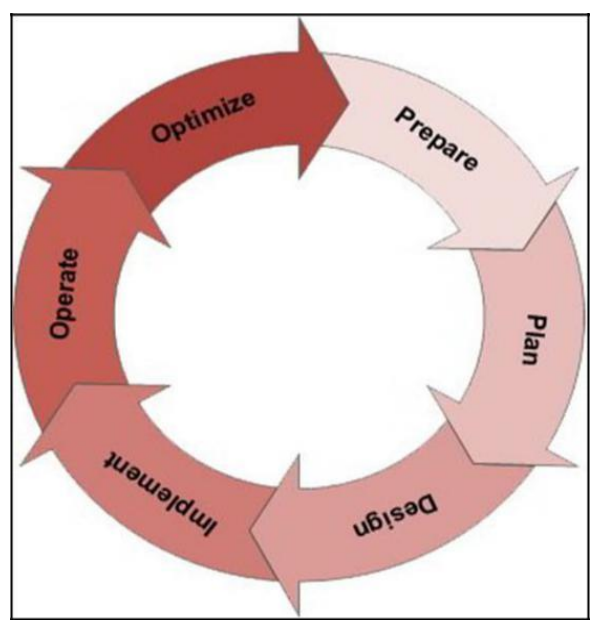

Fig. 1" PPDIOO Model"

\section{Proposed system}

The project work in this study is not only for the experience, but for the purpose of trading in the company can sell this technology to companies that need the work of the Internet of Things, which will help them through it in safety and security matters. Therefore, the comparison between the existing methodology and choose the best one for the project was given in this network system using PPDIOO model. The proposed system includes the following design for a secured network environment as shown in the "Fig. 2":

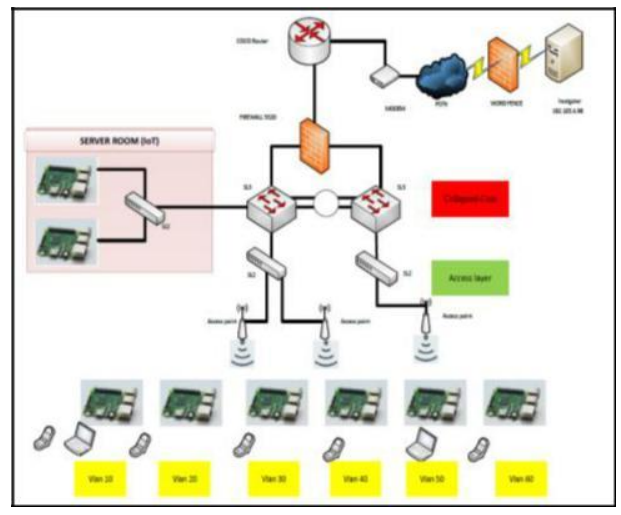

Fig.2 "Proposed Network Infrastructure"

Post Implementation Acceptance test: This test was carried out for all network resources in order to make sure that the new system is at the accepted level for the company environment and the design is perfect for their work environment and received feedback from work team of the engineers of technical in the company in the name of user acceptance criteria such as: The interface of system: it should be easy when the user is using to contact with the system in good way and be share that the user is accepting the proposed system. Performance and the speed: every company looking for system that work fast to allow company to do the work in short time and fast.

Security: every user shod have user name and password to allow them access to the system to use the deferent application.

\section{Conclusion}

In order to help the company and to upgrade their network infrastructure which in turn focuses two reason, first the possibility of work done based on the knowledge which I learnt out of experience and by applying and secondly by activating the available system with more secured real time environment to help the company by explaining them that is possible based on their budget that to be offered by the company enthusiastic for the upgradation. This project enables communication with the Office of Security and Safety notified about any event, and send an email or notified through the Monitoring screen. In each room will have Sensors and is allowed to send data through the Internet to the server. In the case of sense of something that will send a notice warning of the Office of Security and safety. Through IOT it can be monitored through the smart phone application through internet.

\section{Acknowledgement}

First of the all I thank Allah who offers to me able to do the work on this study, after that express thanks to my supervisor Indrani PalaniSamy who guides me from the beginning with advice and teaching me how to complete the report. 


\section{References}

Imura, T., (2015). Internet of Things 101: Getting Started w/ Raspberry Pi. [Online] Available at: https://www.pubnub.com/blog/2015-05-27-internet-ofthings-101-getting-started-w-raspberry-pi/ [Accessed 10 Dec 2016].

Kobie, (2016). Home News \& Blogs Tech blog Internet of things (IoT) with Cortana, Raspberry Pi and a weather sensor. [Online] Available at: https://www.theta.co.nz/news-blogs/tech-blog/internet-ofthings-iot-with-cortana-raspberry-pi-and-a-weathersensor. [Accessed 11 Dec 2016].

Shukri, (2016). MQ-2 Smoke Sensor Circuit Built with an Arduino. [Online] , Available at: http://www.learningaboutelectronics.com/Articles/MQ-2smoke-sensor-circuit-with-arduino.php. [Accessed 13 Dec 2016].

Sean, (2015). How to Build a LM35 Temperature Sensor Circuit. [Online] Available at: http://www.learningaboutelectronics.com/Articles/LM35temperature-sensor-circuit.php. [Accessed 15 Dec 2016].

Hucaby, D. J. \&. D., (2009). Cisco LAN Switching Configuration Handbook. Cisco Press ed. USA: Indianapolis.

Anon., (2016). TP-Link Network TL-WA901ND 300Mbps Wireless N Access Point Retail |TL-WA901ND| Networking. [Online] Available at: https://www.shop.ca/c/tp-link-tl-wa901nd-wireless-nrouter-24431488 [Accessed 20 Dec 2016].

Jose, S., (2016). End-of-Sale and End-of-Life Announcement for the Cisco ASA 5520 Adaptive Security Appliance. [Online] Available at: http://www.cisco.com/c/en/us/products/collateral/sec urity/asa-5500-series-next-generation-firewalls/eol_C51727279.html [Accessed 12 Dec 2016]. 